\title{
Experimental Investigations using partial Porous Medium inside the Channels of Flat Plate Solar Water Collectors
}

\section{G. Iordanou}

New and Renewable Energy Group, School of Engineering and Computing Science, Durham University, Durham, U.K.

Received 7 July 2012; Accepted 22 February 2012

\begin{abstract}
Commercial solar water heating collectors are usually oversized in order to satisfy a heat demand and this increases their manufacturing cost. It is possible to reduce the size of collectors if heat transfer from the channel walls to the working fluid is increased. To enhance the heat transfer to the working fluid a metal porous medium placed inside pipes. The presence of a metal porous medium made of aluminium or stainless steel results in the increase of the interface between the fluid and absorber, diffusion in the near wall flow and increases in the heat transfer rate. The aim of this study is to experimentally investigate the effect of heat transfer inside the channels, partially filled with porous medium, of a simplified flat plate solar water collector for application in the Southern Europe.
\end{abstract}

Keywords: Flat plate collectors, solar energy, enhanced heat transfer, partial metal porous medium, manufacturing cost.

\section{Introduction}

In recent years solar energy has be given a great consideration as a feasible source of energy source. One of the simplest and direct applications of solar energy is the conversion of solar radiation into heat. A way that the domestic sector can lessen its impact on the environment is by the installation of solar flat plate collectors to heat up water. They have been in service for the last 40-50 years without significant changes in their design and operation principles. A typical flat-plate collector consists of an absorber in an insulated box with transparent cover sheets (glazing). The absorber is usually made of a sheet of high thermal conductivity metal such as copper or aluminium, with integrated or attached tubes. Its surface is coated with a special selective material to maximise radiant energy absorption and to minimise radiant emission. The insulated box reduces heat losses from the back and sides of the collector [1].

In solar water collectors incident solar radiation is converted to heat and passed on to a working fluid such as water. Therefore effective heat transfer is important with the aim to assist the energy conversion process.

The flow distribution through the collector's finned tubes clearly affects the operational efficiency of the collector system as it decreases due to the uniformity of flow being reduced [2-3]. Therefore, the more uniform the flow is through the tubes, the higher is the efficiency of the collector [4-5]. Study shows that non-uniformity of the flow has detrimental effect on the thermal performance of the collector array and this was established by both numerical and experimental investigations [6]. Research to demonstrate

\footnotetext{
*E-mail address: greor@msn.com

ISSN: 1791-2377 @ 2012 Kavala Institute of Technology. All rights reserved.
}

the sensitivity of the flow distribution to the collector's geometry and hydraulic resistance was conducted by Weitbrecht [7]. Bajura and Jones [8] also demonstrated that the geometry of channels determine formation of a nonuniform flow distribution in collector systems. The distribution of the flow can be approximately gauged by temperature measurements at various points of the collector.

Heat transfer enhancement in collectors can be achieved by affecting the boundary layer, which in effect provides a resistance to heat transfer, and increasing heat transfer interface area. The thicker the boundary layer the lower the heat magnitude of the transfer coefficient [9]. A variety of heat transfer enhancing techniques have been investigated and described in relevant literature, see for example Webb [10] and Bergles [11].

Heat transfer enhancement methods can be classified into two categories: (a) passive methods requiring no direct application of external power or (b) active methods, which require external power. One passive method that is widely used to enhance heat transfer between the working liquid and the metal part of the collector is the application of a metal porous medium placed in channels of heat exchangers [12-13].

The presence of a metal porous medium (stainless steel, aluminium, etc.) inside a pipe causes a better thermal dispersion and also increases the interface between the fluid and absorber. The overall thermal conductivity in this case is considerably higher than that of the water. Disadvantage of using porous medium is the rise in the hydraulic resistance [14]. It is also possible to obtain higher heat transfer rates using a pulsating flow through a pipe partially filled with a porous medium. When using such an arrangement the frictional losses will be lower than in the case when a pipe is fully filled by porous medium. Heat transfer for natural or forced convections in a system with channels partially filled 
by a porous material has been the subject to numerous investigations; see for example Poulikakos and Kazmierczak [15]. Research results show the increased heat transfer in an annular duct partially filled with a porous medium with a high permeability and conductivity.

The aim of this study was to investigate experimentally the effect of placing a partial porous medium inside the channels of a simplified flat plate solar water collector for application in Southern Europe.

\section{Experimental Work and Results}

The experimental work involved tests conducted on the rig equipped with two types of solar collector unglazed panels and artificial insolation. The first type used was similar to a conventional design and the second one had a metallic porous material inserted in all its pipes. Each panel consists of 4 sections which are in fact separate tubes with attached fins and these are $1.35 \mathrm{~m}$ long.

The two central sections of the panel have copper pipes with aluminium alloy fins. The sections which are placed on each side of the panel have pipes and fins fully made of copper. All the pipes have an external radius of $10 \mathrm{~mm}$ and fins are $110 \mathrm{~mm}$ in the width. Aluminium alloy fins and copper fins have thickness of 1.5 and $0.5 \mathrm{~mm}$, respectively. Pipes of the panel are connected at the top to a manifold. This manifold is linked to the inlet of a cylindrical water jacket which dissipates heat produced by the collector panels. From the outlet of the water jacket the fluid is directed to the bottom manifold of the panel. The absorption side of the panel is matt black painted. The collector panels are placed in separate wooden boxes with fibre glass insulation beneath, see Figure 1 .

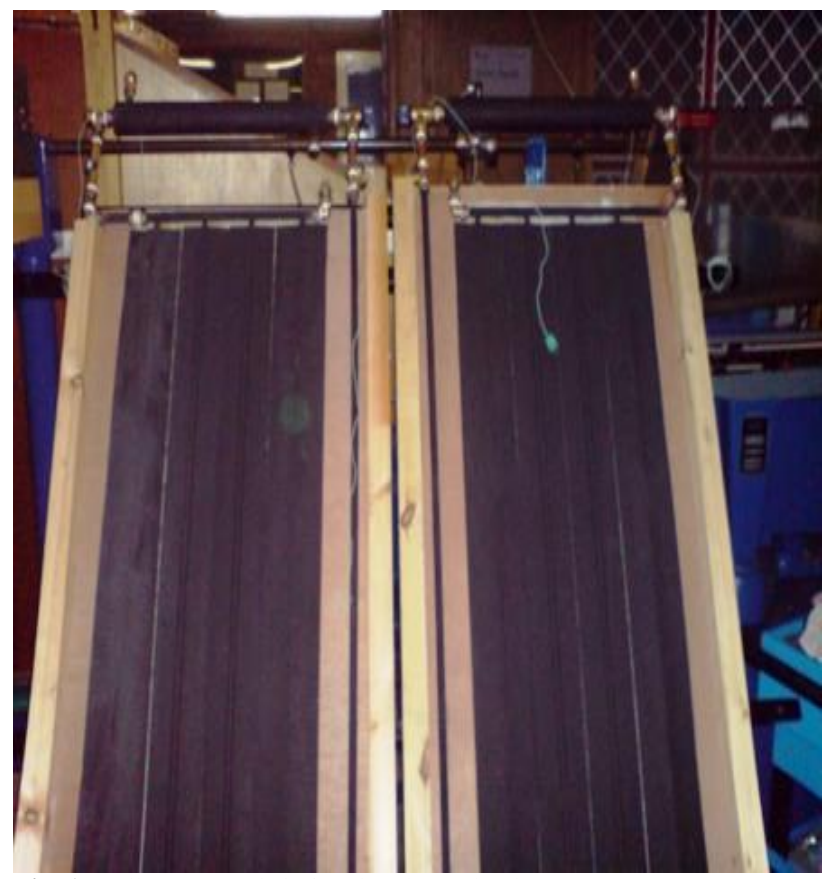

Fig. 1. Collector panels in insulated wooden boxes

The boxes were mounted side by side on the slopped metallic frame. An array of electrical bulbs is mounted above panels parallel to the wooden boxes to imitate insolation. There were a hundred and ten $150 \mathrm{~W}$ halogen floodlights in the array that are evenly spaced over the area of $1.8 \mathrm{~m}^{2}$, see Figure 2 .

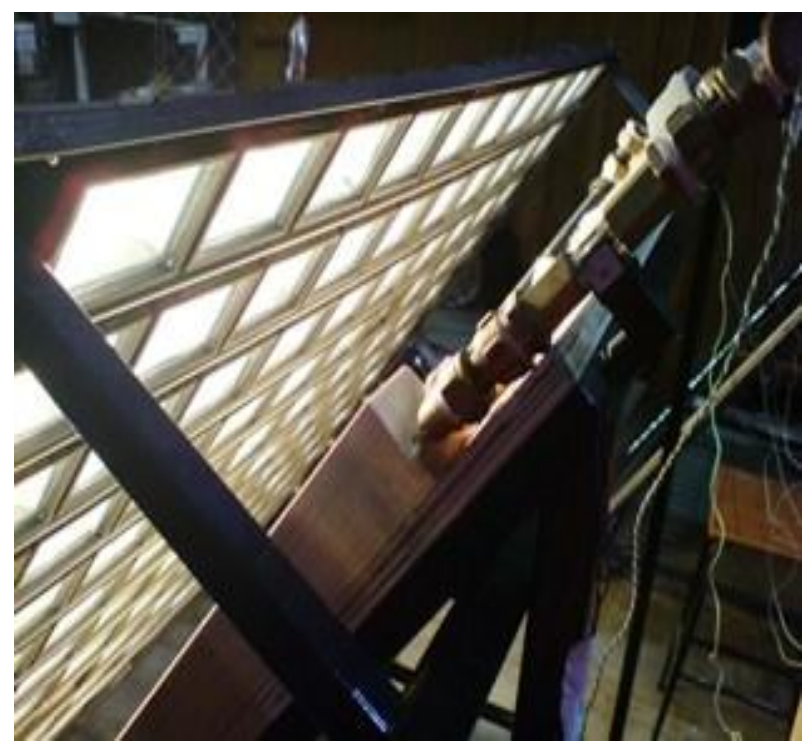

Fig. 2. Array of bulbs mounted above the solar panels

Halogen floodlights are split into three groups and the heat flux from bulbs can be controlled using an electrical three phase transformer.

The porous medium used in one of panels is made of the aluminium wire mesh which was folded and placed in each pipe to provide reasonably even porosity along the length of the channel, see Figure 3.

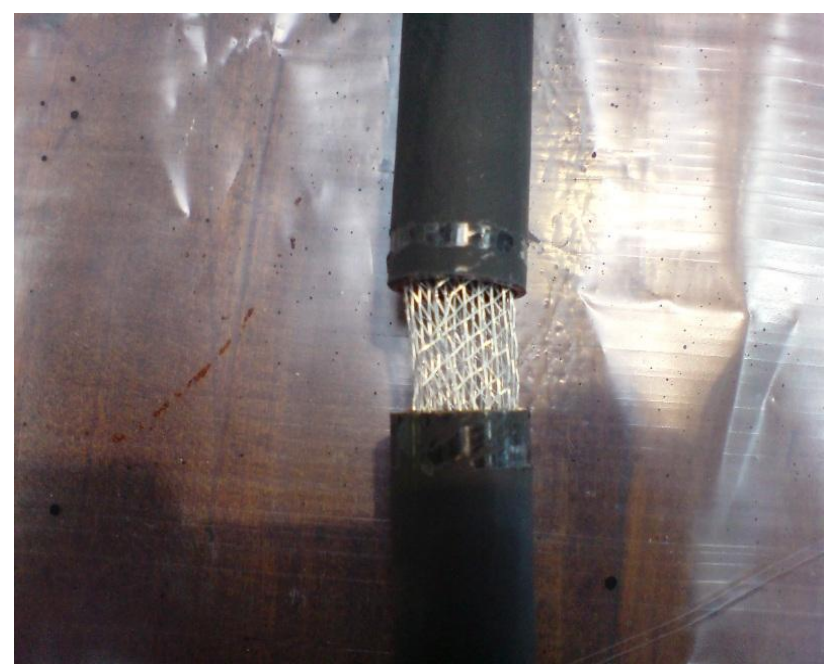

Fig. 3. Porous medium inserted in a copper pipe

A series of K-type thermocouples were installed on each panel that are measuring temperature of the water in the collector at its inlet and outlet and there is additional thermocouple which measures temperature in the water jacket. The water jacket in this case is used as a small water storage tank. Also a portable thermometer with a thermocouple was used to measure the temperature on the surface of the panels at different locations. The volumetric flow rate of the fluid in the panels was determined using flow sensors which were connected to an oscilloscope. 
Three sets of experiments were conducted and the results obtained were averaged, even though the readings were pretty close in all the sets. Each test lasted for about 130 minutes and during the first 60 minutes a heat flux of $500 \mathrm{~W} / \mathrm{m}^{2}$ was applied and then this value was increased up to $700 \mathrm{~W} / \mathrm{m}^{2}$. The level of the heat flux was measured before the commencement of the experiments using a pyranometer.

In Figure 4 a Schematic of the experimental setup is illustrated containing: 1-Water Jacket; 2-Flow sensor; 3-Flat plate collector; 4-Oscilloscope; 5-Power supply; 6-Laptop; 7-Data logger; T1, T2, T3 are thermocouples connected to the data logger that measured temperatures at the inlet, outlet and in the water jacket.

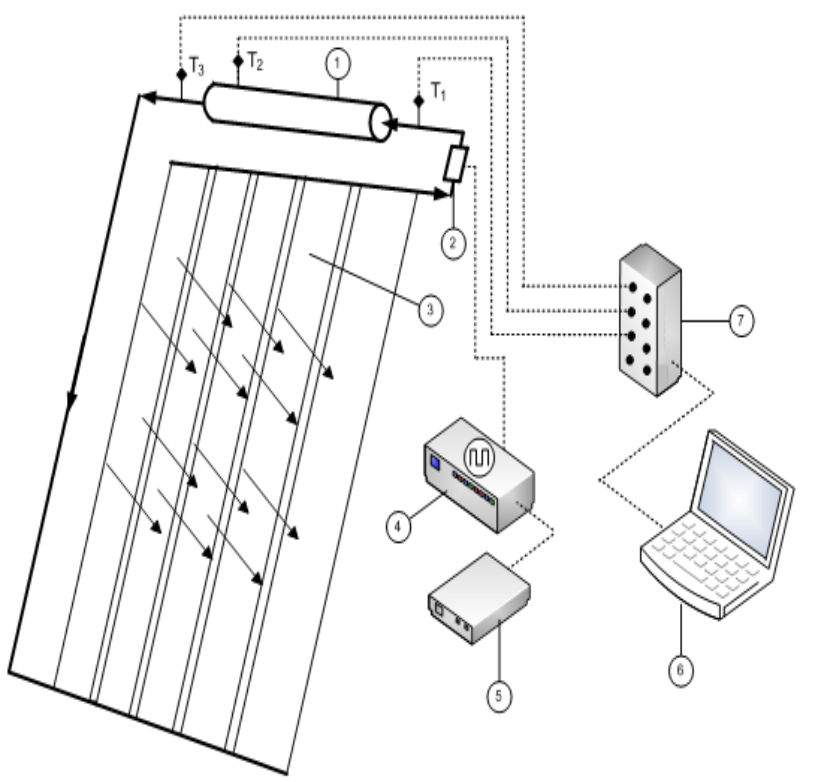

Fig. 4. The experimental Setup

The collector panels were filled up with water from the mains having a temperature of $15^{\circ} \mathrm{C}$. The results obtained using the experimental setup described in the previously were tabulated and graphs plotted relating temperature variations versus time. An error analysis was performed in all the experimental results, combining the 'least squares method' and the 'standard error of estimate' where a measure of the scatter of the regression curve is supplied by an estimated value of a temperature $\mathrm{T}$ over time $\mathrm{t}$.

Figure 5 illustrates the variation of the average temperatures of the water at the outlet of the porous medium (Tout 1) and the conventional (Tout 2) solar panels. It can be observed that the porous medium collector provided the higher water temperature in the outlet. The sudden rise on both waveforms at the 60 minutes margin was due to the increase of the heat flux as intended to increase the radiation $\mathrm{e}$ and the response of the system to irradiation changes as it occurs in reality with the sun. The temperature values were recorded using a data logger connected to a PC.

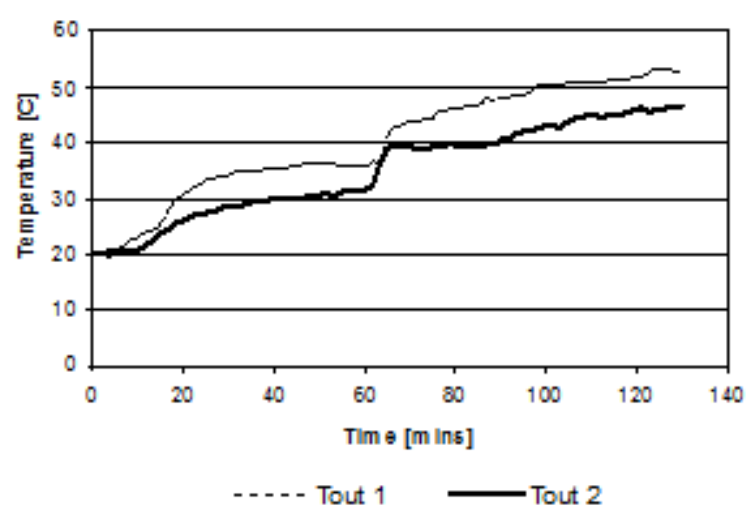

Fig. 5. Outlet water temperature vs. time.

The temperature recorded at steady state, at the outlet of the panel with mesh insertion was $53.04^{\circ} \mathrm{C}$ and for the conventional was $46.78^{\circ} \mathrm{C}$, resulting a remarkable difference in temperature of $6.26^{\circ} \mathrm{C}$. An error analysis using the 'standard error of estimate' method was applied to the experimental results that showed an error of $\pm 0.49^{\circ} \mathrm{C}$ on the recorded temperatures, within the thermocouples calibration range of $\left( \pm 0.6^{\circ} \mathrm{C}\right)$.

Figure 6 illustrates the temperature difference of the water stored inside the water jackets of the porous medium ( $\mathrm{T}$ tank porous) and the conventional one ( $\mathrm{T}$ tank). The temperature recorded when the system reached steady state, at the panel with the mesh insertion was $43.68^{\circ} \mathrm{C}$ and at the conventional one was $37.15^{\circ} \mathrm{C}$, resulting a temperature difference of $6.53^{\circ} \mathrm{C}$. The error analysis performed upon the recorded temperatures, showed an error of $\pm 0.47^{\circ} \mathrm{C}$.

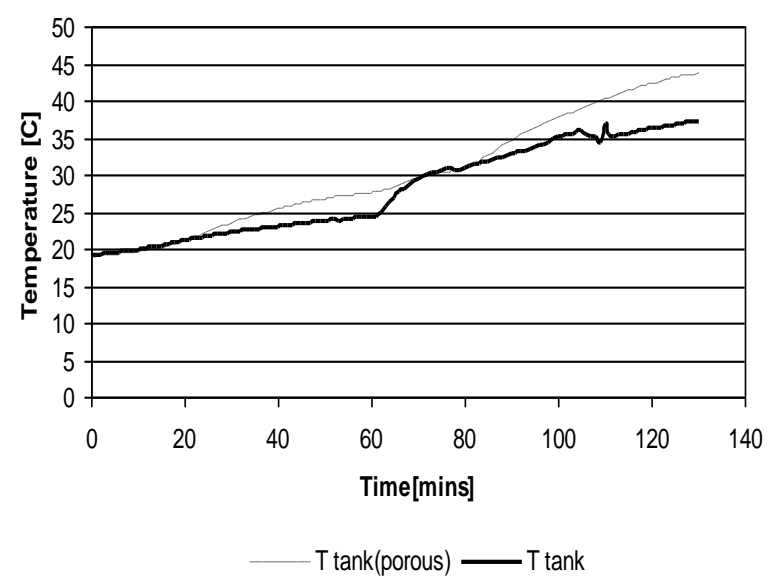

Fig. 6. Water jacket's temperature vs. time

A series of K-type thermocouples were attached onto the surface of each of the panels so more accurate and instantaneous temperature readings could be recorded. They were placed as pairs in each of the finned pipes as shown in Figure 7. All thermocouples were positioned half way along the length of each of the panels. One thermocouple was placed on the fin to measure the fin temperature and the second at the joint between the pipe and the fin to measure the so called base temperature $T_{b}$ important factor for further analysis of the system i.e. the heat transfer coefficient $h$.

From the recorded data the local Rayleigh number for each case was calculated from: 
$R a=\frac{g \beta \Delta T D^{3}}{v \alpha}$

where $g$ is the gravitational force, $\beta$ is the thermal expansion coefficient, $\Delta T$ is the wall and ambient temperature, $D$ is the diameter of the pipe, $v$ the kinematic viscosity and $\alpha$ is the thermal diffusivity. The results showed that the convective forces are dominant in both geometries as they are well in the range of the free convection limits. A higher $R a$ number was obtained for the case with porous medium.

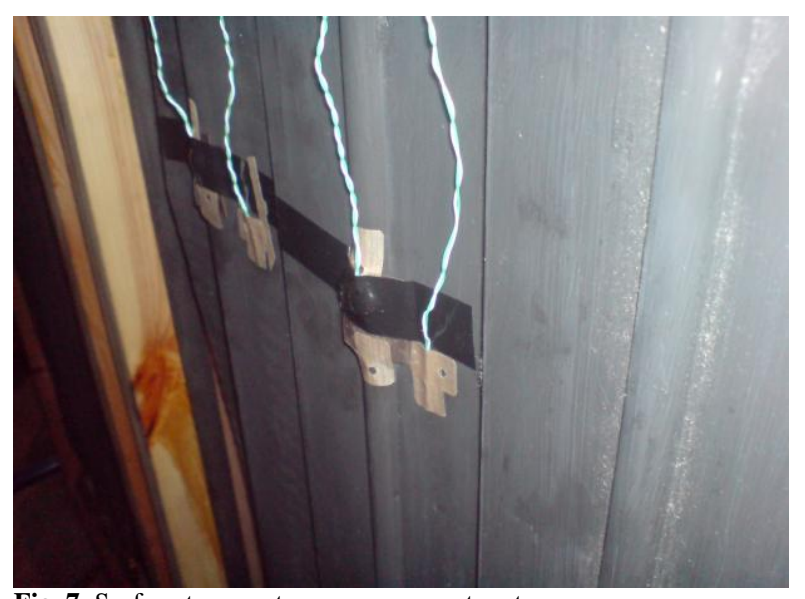

Fig. 7. Surface temperature measurements setup.

The heat transfer coefficient was obtained from the expression:

$$
h=\frac{Q}{\left(T_{b}-T_{\text {fref }}\right)}
$$

where $Q$ is the heat flux in $\mathrm{W} / \mathrm{m}^{2}, T_{b}$ is the temperature at the joint of the fin and pipe and $T_{\text {fref }}$ is the fluid reference temperature in ${ }^{\circ} \mathrm{C}$.
The range of $R a$ Number obtained in both cases suggested that the natural convection was the dominant mode of heat transfer. The heat transfer correlation relating Nusselt $(\mathrm{Nu})$ and Rayleigh $(R a)$ Numbers was sought in the following form:

$$
N i t=d(R)^{n}
$$

here $c$ is the constant of proportionality and $n$ is a variable determined by conditions on the constant heat flux surfaces or isothermal surfaces. This $n$ coefficient was calculated and its average was used to calculate $c$.

\section{Conclusions}

On the whole, the experimental results showed that the metallic mesh inserted in the collector, provided a higher water temperature compared to the conventional collector and it is the presence of the aluminium mesh inside the channels that distributes heat more evenly. The error analysis performed in all the experimental data verified the accuracy of the findings. It was apparent that using partially filled porous mesh in the pipes the heat transfer area increased. The roughness of the aluminium net created a thermal diffusion at the boundary layer that could make the collector more efficient.

The average $R a$ and $\mathrm{Nu}$ numbers obtained for the heat flux of $1070 \mathrm{~W} / \mathrm{m}^{2}$ and $610 \mathrm{~W} / \mathrm{m}^{2}$ were higher in the collector that utilised the aluminium mesh, compared to the conventional and in both cases they showed a good agreement to the expression (3).

Using the porous medium could allow engineers and manufacturers to reduce the area of the solar collector and associated manufacturing costs.

\section{References}

1. Duffie, J. A. and Beckman, W. A. Solar Engineering of Thermal Processes. John Wiley \& Sons, New York, 1991.

2. Chiou, J.P. The effect of non-uniform fluid flow distribution on the thermal performance of solar collector. Solar Energy 29 487-502, 1982

3. Jianhua Fan, Louise Jivan Shah and Simon Furbo. Flow distribution in a solar collector panel with horizontally inclined absorber strips. Solar Energy, ISES 2005.

4. Jones G. and Lior, N. Flow distribution in manifold solar collectors with negligible buoyancy effects. Solar Energy, 52, 1994.

5. Solar Thermal Tech. Sandia National Labs:http://solstice.crest.org/renewable

6. Wang, X. A. and Wu, L. G. Analysis and performance of flat plate solar collector arrays. Solar Energy, 45, 1990.

7. Weitbrecht V, Lehmann D. Richter A. Flow distribution in solar collectors with laminar flow conditions, Solar Energy Volume 73, Issue 6, Pages 433-441 2002.

8. Bajura, R.A. and Jones, E.H.,. Flow distribution manifolds. J. Fluids Eng. Trans. ASME 98, pp. 654-665,1976
9. Francis de Winter. Heat transfer coefficients from bare flat solar heat collectors, 2002.

10. Webb, R. L. Principles of Enhanced Heat Transfer, Wiley, N.Y. 1994.

11. Bergles A.E. Techniques to enhance heat transfer. W.M. Rosehnow et al. (Editors). Handbook of Heat Transfer, McGrawHill, N.Y. 1998.

12. Nield, A.D. and Bejan, A. Convection in Porous Media, Springer Verlag, N.Y., 1999.

13. Baytas A.C and Pop I. Free convection in a square porous cavity using a thermal non-equilibrium model. International Journal of Thermal Sciences, Vol. 41, 2000.

14. Zhixiong Guo. Pulsating flow and heat transfer in a pipe partially filled with porous medium. Int. J. Heat Mass Transfer, Vol. 40, 1997.

15. Poulikakos D and Kazmierczak M. Forced convection in a duct partially filled with porous material. ASME Journal of Heat Transfer, Vol. 109, 1996. 